\title{
Historiografia literária e pós-colonialismo: o caso da literatura indo-portuguesa
}

\section{Literary history and postcolonialism: the case of indo-portuguese literature}

Mestre em Literaturas Modernas, Comparadas e Pós-coloniais pela Università d Bologna e doutoranda em Estudos Com paratistas pela Universidade de Lisboa, comparativo entre as historiografias litedanielaspina@libero.it
RESUMO: 0 presente artigo intenta traçar um panorama sobre a produção historiográfica da literatura indo-portuguesa publicada depois de 1961, ano do fim da ocupação portuguesa de Goa e da sua anexação à União Indiana. Serão analisados dois textos historiográficos considerados fundamentais no estudo da literatura de Goa, ou seja, Esboço da História da Literatura Indo-portuguesa de padre Filinto Cristo Dias de 1963 e A Literatura Indo-portuguesa de Vimala Devi e Manuel de Seabra de 1971. Apesar de serem as primeiras histórias literárias redigidas na época pós-colonial, ambos textos parecem reproduzir ainda uma certa retórica colonialista que se reflete na estruturação da obra, bem como na escolha de datar as origens desta literatura com o começo da empresa colonial portuguesa na Índia, incluindo também as obras literárias dos séculos XVI, XVII e XVIII. Estes dois casos serão comparados com dois textos publicados em 2012 que substituem a definição literatura indo-portuguesa pela expressão literatura goesa em português, reivindicando a autonomia desta última em relação à literatura do colonizador. Os dois livros em questão são Oriente e Ocidente na Literatura Goesa de padre Eufemiano de Jesus Miranda e Literatura Goesa em Português nos Séculos XIX e XX de Joana Passos. Por último, será abordado o problema da literatura da diáspora e da sua colocação no interno da história literária de Goa, pela ajuda do texto de Peter Nazareth Pivoting on the Point of the Return - Modern Goan Literature de 2010.

Palavras-chaves: Historiografia literária indo-portuguesa; Literatura de Goa em português; Estudos Pós-coloniais; Literatura da diáspora.

ABSTRACT: This paper tries to give an overview on the historical production of the Indo-Portuguese Literature published after 1961, the year of the end of the Portuguese occupation of Goa and its annexation to the Indian Union. Two historiographical texts considered fundamental in the study of Goan Literature will be analyzed, those are Esboço da História da Literatura Indo-portuguesa by priest Filinto Cristo Dias from 1963 and A Literatura Indo-portuguesa by Vimala Devi and Manuel de Seabra from 1971. Although being the first literary stories written in the Postcolonial era, both texts seem to still play a certain colonialist rhetoric, which is reflected in the work structure and the choice of dating the origins of this literature with the beginning of the Portuguese colonial enterprise in India, including also the literary works of the Sixteenth, Seventeenth and Eighteenth centuries. These cases will be compared with two texts published in 2012, replacing the definition of Indo-Portuguese Literature with the expression Goan Literature in Portuguese, claiming the autonomy of the latter in relation to the colonizer's literature. The two books in question are Oriente e Ocidente na Literatura Goesa by priest Eufemiano de Jesus Miranda and Literatura Goesa em Português nos Séculos XIX e XX by Joana Passos. Finally, we shal discuss the problem of Diaspora Literature and their placing on the Literary History of Goa, with the help of Peter Nazareth's text Pivoting on the Point of the Return - Modern Goan Literature of 2010.

KEYwORDS: Indo-Portuguese Literary History; Goan Literature in Portuguese; Postcolonial Studies; Diaspora Literature. 
$\gamma \mathrm{a}$ alar de história literária não é uma tarefa simples, nunca foi e hoje continua a não ser, especialmente numa época em que o discurso historiográfico e o discurso nacional deixaram de funcionar como binómio indissolúvel. Se a história da literatura, entendida como género, desabrocha no século XIX como instrumento de narração e consagração da história das nações europeias recém-nascidas, no século XX assistimos à emersão de novos contextos geopolíticos, para os quais é exigida uma reinterpretação do conceito de história e história literária. Um dos exemplos que poderiam ser observados é o caso oferecido pelos países formados a partir da dissolução dos regimes coloniais, assim como pelas mudanças políticas e sociais provocadas pelos efeitos do processo de descolonização, entre os quais, por exemplo, é de mencionar o fenómeno da diáspora.

Com o advento dos Estudos Pós-coloniais, começou a ganhar força a ideia da reescrita da história, a partir da desconstrução do passado e da tentativa de reconstrução de identidades culturais rasgadas pelas relações de poder e violência subjacentes ao mundo colonial. Neste processo de reavaliação do passado, onde a voz narradora passa da posição hegemónica do colonizador para a subalterna do colonizado - conforme a leitura de Gramsci feita pelos Subaltern Studies -, a literatura ocupa um lugar privilegiado, desenvolvendo uma verdadeira função de arquivo e constituindo uma arma de reivindicação do direito dessas identidades a existirem.

À luz disto, a história da literatura não deve ser contemplada apenas como narração de eventos e fenómenos literários, mas como um processo contínuo de construção e reapropriação de formas, géneros e temas. 0 estudo desta historiografia, nesta perspetiva, comporta a averiguação de como a literatura foi sendo, ao longo do tempo, percebida e reconcebida e de como a experiência do colonialismo terá influído no seu decurso evolutivo.

No debate atual sobre a narração das histórias das literaturas surgidas a partir da experiência colonial de Portugal, a historiografia da literatura indo-portuguesa assume conotações problemáticas que podem ser notadas já a partir do nome que a designa. Essa forma "hifenizada", muito debatida e criticada ao longo dos últimos anos, confere a essa literatura um caráter complexo que questiona a sua natureza híbrida. A presença do hífen oferece uma dúplice leitura que pode ser indicadora da união entre os dois termos ou da crise que carateriza a relação entre estes. Uma crise que pode ser superada elaborando uma atenta análise do processo de formação dessa literatura, reconhecendo ou negando a sua autonomia em relação à herança cultural do colonizador. Isso levou muitos estudiosos que se ocuparam de enfrentar os problemas inerentes à literatura de Goa, a cunhar novas expressões que sublinhassem a exigência de se aligeirar do peso do termo "portuguesa", para abordar uma perspetiva que dialogasse, em medida maior, com o seu caráter literariamente autónomo. 0 resultado foi a aparição de numerosos trabalhos sobre a "literatura de Goa em português" que problematizavam não apenas a sua forma nominal, mas também a datação das origens da sua história, conforme a inclusão ou exclusão da produção literária dos primeiros três séculos de colonização, reconduzível a uma literatura muito próxima de Portugal e que é testemunho do enraizamento do poder imperial português na Índia.

Entre as histórias literárias que defendem a inclusão de tal período, a mais importante é sem dúvida A Literatura Indo-portuguesa de Vimala Devi e Manuel de Seabra, publicada em Portugal em 1971 e a partir da qual o interesse pela história da literatura de Goa começa a difundir-se pela Europa. Os dois autores reconstruem a história, datando as origens desta literatura com a chegada dos portugueses à Índia e portanto reconduzem o seu começo às primeiras escritas religiosas produzidas pelos clérigos. A escolha de colocar o início da literatura indo-portuguesa em tempos tão remotos é justificável através do entendimento do espaço e contexto histórico em que a obra foi concebida. 
Publicados exatamente a dez anos da incorporação de Goa à União Indiana, A literatura Indo-portuguesa e o texto antológico anexo foram financiados pela Junta de Investigações do Ultramar, na época do governo de Marcelo Caetano e em plena guerra colonial na África. Tudo isso repercute-se na ideologia à base dos textos que parecem reproduzir uma certa retórica colonialista, notável não apenas nos capítulos introdutivos - onde os autores explicitam o seu projeto historiográfico -, mas também na seleção das obras abordadas.

Não obstante essa obra possa ser entendida como a primeira história literária pós-colonial de Goa, A Literatura Indo-portuguesa reflete toda a precariedade de um pensamento em vias de extinção. Pensamento enfatizado no primeiro capítulo do texto, Goa e os Portugueses, pela alusão ao lusotropicalismo de Gilberto Freyre ${ }^{1}$. Se bem que Vimala Devi e Manuel de Seabra - cônjuges, respetivamente goesa e português - nunca nomeiem diretamente a teoria freyriana, ela é presente sob a forma de citação e é palpável no discurso identitário que eles construem para fundamentar a própria ideia de texto historiográfico:

Diz-se que S. João de Brito, para melhor se identificar com os povos do Oriente, "se fez bronzear com unguentos da cabeça ao pés, tornando-se assim igual no corpo aos mesmos indianos". Esta atitude, por espantosa que pareça, representa, de facto uma atitude de civilização que poucos povos tiveram a coragem de assumir e que tornou possível a um país com pouco mais de um milhão e meio de habitantes não apenas sustentar um dos mais extensos impérios da História, numa época de precários meios de comunicação, mas também - e principalmente - dar origem a tipos peculiares de civilização, dos quais o Brasil e Goa são talvez os exemplos mais flagrantes. (DEVI; SEABRA, 1971, p. 11)

1 O conceito de lusotropicalismo foi apresentado pela primeira vez por Gilberto Freyre em novembro de 1951 em Goa, no Instituto Vasco da Gama em Panjim (hoje Instituto Menezes Bragança)
Expressões como atitude de civilização ou tipos peculiares de civilização ressoam como o eco de um passado ainda muito próximo. Estamos diante de um texto historiográfico pós-colonial imergido num contexto histórico e cultural ainda impregnado de colonialismo, fator que influi na maneira com que é tratada a matéria literária. Para provar isso, veja-se como os dois autores manifestam a exigência de definir o que é a literatura indoportuguesa a partir do hibridismo que conota a formação cultural do povo goês:

Até que ponto - é o problema que enfrentamos - o povo goês é culturalmente ele? Será o povo goês culturalmente indiano, português, ou luso-indiano, ou simplesmente goês?

Ao contemplar a paisagem humana e cultural de Goa, não pode o observador deixar de meditar no mistério de uma sociedade que, não sendo totalmente indiana, também não é totalmente portuguesa. (DEVI; SEABRA, 1971, p. 16-17)

A questão que eles colocam é indubitavelmente importante para entender a essência desse fenómeno literário, mas, como é possível notar, a resposta inclui uma referência ao milagre da suposta missão humanitária e civilizadora dos portugueses - repare-se na expressão "meditar no mistério" -, o que nos faz hesitar sobre a objetividade da implantação ideológica da obra.

$\mathrm{Na}$ estruturação do texto historiográfico, entre o quinto e o sexto capítulo, Vimala Devi e Manuel de Seabra cumprem uma distinção entre os primeiros escritores goeses em língua portuguesa e o aparecimento de uma verdadeira expressão literária indo-portuguesa. ${ }^{2}$ Para Devi e Seabra a literatura de Goa compreende também as escritas que remontam ao século $\mathrm{XVII}$, as obras daqueles escritores que apesar de terem nascido em Portugal,

2 As expressões em itálico correspondem aos títulos dos dois capítulos em questão. 
transcorreram parte da vida em Goa ou assumiram Goa como ponto da sua enunciação. Nesse elenco aparecem António Galvão - em absoluto o primeiro escritor goês de língua portuguesa (DEVI; SEABRA, 1971, p. 113) -, Jorge de Lemos, Fernão Alvares do Oriente, Baltasar da Costa, André Balão, Lourenço Pires e Manuel Jácome de Mesquita. A respeito disso, escrevem:

E aqui uma dúvida surge. Será lícito incluir europeus numa panorâmica da literatura goesa? Trata-se de problema melindroso e que já tem sido longamente debatido [...] 0 problema é de difícil, senão impossível, solução, e tudo depende do critério, da posição que for assumida perante a cultura das nações envolvidas. Apresentado, porém, exemplos mais chegados a nós, serão José Basílio da Gama, Santa Rita Durão, Tomás António Gonzaga ou Sousa Caldas poetas brasileiros ou poetas portugueses de expressão americana? (DEVI; SEABRA, 1971, p. 113)

A menção do caso da literatura brasileira - outra literatura surgida a partir da experiência colonial portuguesa - salienta a intenção dos autores de escrever uma história literária que dialogue com as outras literaturas de língua portuguesa. $\mathrm{O}$ ato de considerar a obra de autores portugueses que escreveram a partir de Goa como parte da literatura goesa procede da intenção de enfatizar o aporte da herança colonial na formação da mesma. Devi e Seabra explicam como nas primeiras décadas da Goa colónia, o apagamento da cultura hindu e a difusão da cultura luso-cristấ ${ }^{3}$ deixaram que fosse essa última a lançar os alicerces para o nascimento futuro de uma literatura propriamente indo-portuguesa.

A sucessiva diferenciação que eles elaboram entre literatura de Goa em português e literatura indo-portuguesa - e por tanto o critério definitório adotado durante a construção desta obra - baseia-se no reconhecimento de uma série de documentos literários, em que é possível individuar a marca

3 Expressão utilizada por Gilberto Freyre na já citada conferência de Goa em 1951. de uma sociedade já formada sob o signo da simbiose cultural luso-indiana. Na opinião deles, em Goa esse processo formativo tardou um século e meio e completou-se com a aparição de três obras cujos autores cristãos assumem uma posição castista (DEVI; SEABRA, p. 115). O raciocínio de Devi e Seabra funda-se no fato que o conúbio entre as duas culturas, portuguesa e indiana, acontece não apenas com a conversão forçada do hindu ao cristianismo, mas também com a adoção de atitudes castistas por parte dos expoentes das ordens religiosas cristãs ${ }^{4}$. Por essa razão reconhecem o início da literatura indo-portuguesa - diferente da literatura de Goa - em Tratado Apologético contra varias calumnias impostas pela malevolência contra a sua Nação Bracmana de 1686 de padre Francisco do Rego, Avreola dos Indios \& Nobiliarchia Bracmana, escrito em 1702 por padre António João de Frias e Promptuario das Diffiniçoens Indicas aparecido em 1713, realizado pela mão do padre Leonardo Pais.

As últimas duas obras voltam a ser citadas pelos autores de $A$ Literatura Indo-Portuguesa no sucessivo capítulo O Resssurgimento Cultural de Goa, onde questionam o fato de que as obras mais significantes da literatura indo-portuguesa tenham sido publicadas em Lisboa, fator que impediu a contribuição destas à formação de uma superstrutura cultural em Goa (DEVI; SEABRA, 1971, p. 131). Devi e Seabra não se referem simplesmente à censura e aos períodos de interrupção da atividade da imprensa em Goa - acontecidos de 1574 a 1615 e de 1754 a 1821 -, mas também aos seus períodos de funcionamento regular. Entre as nove obras que eles citam, aparecem Aureola de António João de Frias e Promptuario de Leonardo Pais, as quais "por cristalizarem em si o problema básico do novo homem

4 "As castas persistiram e dominaram, e o Cristianismo não tardou, insólitamente, a adaptar-se-lhe. À medida que as várias ordens religiosas entravam em Goa, iam sendo dominadas pelas diferentes castas, principalmente por brâmanes e chardós, as duas castas de mais forte predomínio social." (DEVI; SEABRA, 1971, p. 114). 
indo-português, nunca será demasiado lamentar que não tivesse sido proporcionada a oportunidade de agir" (DEVI; SEABRA, 1971, p. 133), ou seja, de influir na formação de uma consciência literária entre os goeses. A partir da formulação desse problema por parte dos dois autores, podemos notar o contraste existente entre a evidenciação da falta da difusão dessas obras em Goa e a apuração delas como arquétipos da literatura indo-portuguesa. Portanto, para Devi e Seabra estamos diante de uma literatura fundacional que não participa do processo de constituição de uma consciência intelectual, mas que consegue, igualmente, ser parte de uma tradição literária, como explicitado no já mencionado capítulo $O$ Aparecimento de uma verdadeira expressão literária indo-portuguesa.

O mesmo problema da imprensa apresenta-se também entre os séculos XIX e XX, quando são publicados em Portugal, Os Brahamanes de Francisco Luís Gomes (1866), O Signo da Ira de Orlando da Costa (1961), Bodki de Agostinho Fernandes (1962) e o livro de contos Monção de Vimala Devi (1963). Os três romances e a obra da mesma autora do texto historiográfico aqui em análise são considerados as obras mais representativas da literatura de Goa em português, mas ao mesmo tempo "foram também publicadas em Lisboa, privando assim Goa da sua influência directa" (DEVI; SEABRA, 1971, p. 133).

É preciso destacar que a interpretação que Devi e Seabra fazem posteriormente do romance Os Brahamanes de Francisco Luís Gomes é bastante questionável, pois é ocultada a intenção do autor de escrever o primeiro romance anticolonialista do mundo ocidental:

A tese de Francisco Luís Gomes é a injustiça do sistema de castas, que ataca valerosamente, sem, no entanto, lhe apontar uma solução, indispensável num romance de tese como este. Francisco Luís Gomes confunde solução com moral, atitude, de resto, muito corrente. E a moral do seu romance é o triunfo da caridade sobre a paixão, muito a gosto da época, a qual, aliada a uma intriga bem delineada de roman passionnel, faz de Os Brahamanes uma obra que ainda hoje se lê com interesse, pois o autor consegue mesmo comunicar-lhe um forte suspense que prende o leitor (DEVI; SEABRA, 1971, p. 198).

Só é de lamentar que esta obra tivesse sido publicada em Lisboa, e não em Goa, furtando-se assim a uma influência - que poderia ter tido importantes consequências - no ambiente social e psicológico de Goa, pois se trata do mais veemente protesto contra o regime das castas que impera na Índia e também em Goa, mesmo entre a população católica, sem que nunca contra ele se tivesse travado uma luta directa (DEVI; SEABRA, 1971, p. 199).

Concordamos com os dois autores ao escrever que Os Brahamanes é um romance de tese, mas a tese defendida pelo romancista é outra e implica um discurso anticolonialista, apesar da crítica de Francisco Luís Gomes ser dirigida ao colonialismo inglês, sendo o romance ambientando na Índia inglesa.

Se no caso de Os Brahamanes o substrato ideológico do romance é interpretado numa maneira discutível, no caso de $O$ Signo da Ira de Orlando da Costa qualquer referência aos conteúdos da obra é omitida. Esse romance, que apesar de ter sofrido de censura por causa dos seus conteúdos declaradamente anticolonialistas, conseguiu se afirmar como obra de notável importância tanto da literatura portuguesa quanto da goesa. No capítulo dedicado ao género do romance, apesar da premissa do "vale a pena de estudar em pormenores" (DEVI; SEABRA, 1971, p. 206), o aprofundamento limita-se à corrente literária do Neorealismo com a qual a obra costuma ser identificada:

Afastando-se inconscientemente das massas, os escritores neorealistas criaram um estilo elevado e alegórico, fiel aos princípios que os motivaram, mas cada vez mais cultista, denunciando a sua origem pequeno-burguesa.

Com O Signo da Ira, Orlando da Costa, que acompanhara o neo-realismo desde os tempos do 'Novo Cancioneiro', procurou escrever o romance neo-realista de Goa. 
O Signo da Ira possui todas as qualidades e defeitos dos romances neo-realistas da última fase desta escola, grandiloquente e pequeno-burguesa. 0 seu estilo seguiu, exagerando, as tendências desta última fase, e pretende ser altamente poético e alegórico. (DEVI; SEABRA, 1971, p. 207-208)

Essas afirmações são marcadas por uma nota de fim de capítulo que refere: "Posto que $O$ Signo da Ira teve grande divulgação devido ao prémio que lhe foi atribuído, ${ }^{5}$ escusamo-nos a resumi-lo" (DEVI; SEABRA, 1971, p. 215). Entre todos os romances analisados, O Signo da Ira é o único cujos enredo e argumentos não são apresentados, escolha que se justifica provavelmente com o caráter institucional do texto historiográfico. ${ }^{6} \mathrm{Tal}$ caráter molda in totum a compilação dessa história literária que, conforme quanto problematizado no início desse trabalho, ainda sofre de algumas influências da mentalidade colonialista, elemento que nos deixa perplexos a definir esse texto como primeira história pós-colonial da literatura de Goa. Sobre a definição de pós-colonial, entendemos - de acordo com os autores de The Empire Writes Back - não apenas o que pode ser datado no período sucessivo à independência das colónias, mas também toda aquela produção cultural que se conota como oposição ao poder colonial. Por essa razão, $A$ Literatura Indo-portuguesa encontra-se nos limites desta aceção teórica.

Voltando à organização da obra, visto que as origens dessa história são datadas em tempos tão remotos, o imenso corpus de textos com que os autores devem lidar torna a estruturação do trabalho muito complexa. Portanto Devi e Seabra não conseguem focalizar-se numa única tipologia de texto historiográfico, mas distribuem a matéria literária em 22 dos 26

5 O romance obteve o Prémio Ricardo Malheiros em 1962.

6 O Signo da Ira narra da dramática vida dos manducares da aldeia Torsan-Zori (Margão) e das deploráveis condições de trabalho aos quais são submetidos pelo batcar bab Ligor, no contexto dos últimos anos de ocupac̃o militar pelas tropas portuguesas. Relatando os acontecimentos trágicos que movimos anos a existência dos protagonistas do romance, Orlando da Costa denuncia, desta forma, todo um mundo marcado pela iniquidade e pela violência geradas pelo sistema colonial. capítulos que compõem a obra, constituindo os primeiros quatro apenas uma resenha histórica sobre a presença portuguesa na Índia e a sua influência na formação cultural do povo goês. Os restantes apresentam a evolução de específicos géneros literários - nomeadamente a historiografia, o jornalismo, a crítica literária, o ensaio, a literatura de viagens, a linguística, as ciências auxiliares da história, a literatura religiosa, o romance, o conto, o teatro e por fim a poesia -, com exceção de três capítulos dedicados às personalidades do historiógrafo Cunha Rivara, o poeta Tomás Ribeiro e o jornalista e crítico literário Moniz Barreto. Assim sendo, poderíamos identificar A Literatura Indo-Portuguesa como uma história literária híbrida que engloba mais géneros historiográficos, em razão da ânsia dos autores de não deixar nada excluído.

Uma primeira tentativa de reorganizar todos os trabalhos literários realizados em Goa a partir do século XVI já foi feita por padre Filinto Cristo Dias no seu Esboço da História da Literatura Indo-portuguesa, publicado em vários números do Boletim Eclesiástico da Arquidiocese de Goa entre 1957 e 1961, para ser sucessivamente editado num único volume em Goa em 1963, dois anos depois da libertação por parte da União Indiana - evento a que Devi e Seabra se referem mais que uma vez com o termo invasão. Esta edição é introduzida por uma advertência preambular em que o autor explica as motivações que o levaram a empreender um trabalho tão árduo:

Infelizmente de quantos se têm aplicado até hoje ao estudo do nosso passado, nenhum se deu ao trabalho de apreciar o nosso movimento literário metodicamente, isto é, estudando através das vicissitudes da nossa cultura, as influências mesológicas e as que foram exercidas pelo meio exterior sobre os nossos escritores.

Enquanto se não leve a efeito tal empreendimento, pareceu-nos que poderíamos aventurar-nos a tentativas que valham como contributo mais ou menos prestadio para a obra de sistematização da História da Literatura indoportuguesa. 
Elaborando sob o influxo desse considerando, o presente trabalho não aspira a ser mais que uma sinopse quiçá incompleta de materiais dispersos que, pacientemente reunidos e joeirados, com critério científico poderiam oferecer abundante cabedal para se compor um minucioso estudo analítico da nossa evolução literária. (DIAS, 1963, s.p.)

É interessante notar como Filinto Cristo Dias, para referir-se à elaboração da sua obra, use o termo sistematização para realçar o enorme esforço de doar uma forma a todo o conjunto fragmentário de documentos literários e decifrar as linhas evolutivas da literatura indo-portuguesa. Mas a tentativa que o autor cumpre relaciona-se também com a averiguação da existência de uma verdadeira tradição literária, contrariamente a Devi e Seabra, cujo trabalho edifica-se sobre a ideia de já existir em Goa uma tradição, embora fraca e cheia de vazios.

Mas qual é a ideia de literatura indo-portuguesa que o autor do Esboço tem? Depois de ter traçado um breve perfil da Goa pre-lusitana, ou seja, da civilização preexistente à chegada dos portugueses à Índia, no parágrafo Conceito da História da Literatura Indo-portuguesa, ele escreve:

Em linhas gerais era este o grau do desenvolvimento intelectual do goês no princípio do sec. XVI. É então que se lhe descerram horizontes duma nova civilização que a lusa gente lhe traz com a sua crença, com os seus costumes, com o seu idioma.

A língua portuguesa remotamente aparentada com o nosso concani e com as outras línguas de procedência sanscrítica e que já fora veículo duma notável floração literária em Portugal, vai-se agora espalhando no nosso país devido às escolas que se multiplicam e sobe a tal altura a assimilação do novo idioma por parte dum escol sempre crescente dos naturais que não tarda a desabrochar em apreciáveis produções de pensamento e de arte.

Ora o registo e o estudo de todas estas criações pertence à História da Literatura Indo-Portuguesa que poderá ser definida como resenha e crítica de todas as obras, em prosa e verso, escritas pelos goeses que se serviram de português para a expressão das suas ideias e sentimentos. (DIAS, 1963, p. 2-3)
Este conceito de literatura foi fortemente criticado pelos autores de A Literatura Indo-Portuguesa, os quais, numa secção da crítica literária dedicada a Cristo Dias, declaram:

Esta definição não é, porém, respeitada pelo autor, pois não só inclu descendentes como Fernando Leal e Tomás Mourão Garcês Palha - que se podem aceitar desde que seja devidamente qualificado o termo de referência goeses - mas até europeus, paclé, como Gaspar Correia, Fernão Lopes de Castanheda, Diogo do Couto, Joaquim Heliodoro da Cunha Rivara, Tomás Ribeiro e Alberto Osório de Castro. (DEVI; SEABRA 1971, p. 248)

Podemos corroborar, mais uma vez, que para Devi e Seabra a definição de literatura indo-portuguesa não está estritamente ligada à procedência das vozes autorais, mas sim ao lugar a partir do qual tais vozes escrevem, ou seja, Goa. Para eles o aporte da literatura dos primeiros três séculos de colonialismo à formação cultural do goês é absoluto. Por esta razão, não conseguem fugir de um discurso identitário que se torna central ao seu trabalho historiográfico. Pelo contrário, Cristo Dias isenta-se da questão identitária, fato confirmado pela inclusão de autores como Gaspar Correia, Fernão Lopes de Castanheda e Diogo do Couto, referidos simplesmente "pela inteligente curiosidade com que se ocuparam nas suas obras das coisas indianas" (DIAS, 1963, p. 18).

A datação do começo da literatura indo-portuguesa é até mais longínqua que a determinada pelo casal de estudiosos, coincidindo esta com a criação das escolas paroquiais em Goa em 1545. Conforme isso, Filinto Cristo Dias divide a história em três períodos, seguindo um critério cronológico: um primeiro período que inclui os séculos entre 1545 e 1821, ano em que começa a ser publicada a Gazeta de Goa; um segundo momento que abarca boa parte da literatura produzida até 1871, ano da fundação do Instituto Vasco da Gama em Pangim; uma terceira e última fase que chega até a época contemporânea ao autor. 
Proporcionalmente ao reduzido tamanho do livro - composto por pouco mais que 100 páginas - o primeiro período consta apenas de três páginas em que Filinto Cristo Dias ilustra o funcionamento dos primeiros colégios religiosos e menciona os três autores já definidos por Devi e Seabra como os primeiros expoentes da literatura indo-portuguesa, adicionando o nome de Jácome Gonçalves (1676-1742), autor de Vocabulário Chingalá Lusitano, Vocabulário Lusitano Chingalá, Vocabulário Lusitano Tamílico - Chingalá com declaração de frases chingalás. A escassez dessas folhas é provavelmente devida aos dois períodos silenciados da imprensa aos quais aludiam Devi e Seabra no capítulo sobre o ressurgimento cultural de Goa.

Os dois restantes períodos são construídos em maneira mais pormenorizada, interessando uma época em que a produção literária de Goa foi significativamente superior aos séculos anteriores. No segundo período ganha relevo a já citada obra Os Brâmanes de Francisco Luís Gomes - a que o autor dedica bem sete páginas e cuja interpretação provavelmente inspirou Devi e Seabra na sua leitura do romance -, assim como o estudo da historiografia.

No terceiro e último período, cada paragrafo respeita uma subdivisão pelos géneros literários mais desenvolvidos, especificamente o jornalismo, a poesia e a historiografia, exceção feita pela menção num parágrafo separado de Jacob e Dulce de Gip - pseudónimo de Francisco João da Costa -, romance publicado em 1896 no jornal $O$ Ultramar. Este capítulo representa a parte mais copiosa do Esboço devido a "o crescimento espiritual da mensagem literária que a gente lusíada trouxe a este país" (DIAS, 1963, p. 22), contrariamente ao que será sustentado nalguns textos historiográficos a virem, onde a passagem entre os séculos XIX e XX será considerada o ponto de rutura, o momento em que a literatura indo-portuguesa se emancipa e evolui na literatura goesa.
A inclusão da literatura de cunho português como parte integrante da história literária de Goa, suscitou não poucas perplexidades nos trabalhos publicados nos últimos anos pelos especialistas deste âmbito. Mas, apesar dos limites apresentados por A Literatura Indo-portuguesa e Esboço da História da Literatura Indo-portuguesa, os dois - mas em particular modo a primeira - continuam a constituir uma sólida referência para cada estudioso que decide se aproximar a este campo literário. E é possível achar rastos dessas obras também naqueles estudiosos que não compartilham totalmente a ideia de literatura indo-portuguesa defendida nelas.

É verdade que podemos contar numa copiosa produção crítica composta por artigos e teses de doutoramento elaborados nos últimos vinte anos, mas as tentativas de reescrever a história da literatura de Goa foram realmente poucas. Há dois casos que não são exatamente dois textos historiográficos, mas que merecem ser igualmente apontados, por examinarem um retalho fundamental da história da literatura de Goa em português. Estes textos são Oriente e Ocidente na Literatura Goesa: realidade, ficção, história e imaginação do goês padre Eufemiano de Jesus Miranda e Literatura Goesa em Português nos Séculos XIX e XX: Perspectivas Pós-coloniais e Revisão Crítica de Joana Passos, pesquisadora na Universidade do Minho, respetivamente publicados em Goa e em Portugal em 2012.

Oriente e Ocidente na Literatura Goesa corresponde à tese de doutoramento de Eufemiano de Jesus Miranda, defendida na University of Goa em 1994 sob o título de Literatura Indo-portuguesa dos séculos XIX e XX: um estudo de temas principais no contexto sócio-histórico. Fazendo um paralelo entre os dois textos, apesar da alteração do título, os pressupostos teóricos e os conteúdos não mudam. Na sua explicação do termo indo-português, o autor da tese baseia-se na definição cunhada por Sousa Viterbo em fins dó século XIX para se referir "aos objetos feitos na Índia por artesãos indígenas, 
ou, em Portugal sob a influência indiana" (SOUSA in MIRANDA, 2012, p. 17). A aplicação desse termo à literatura, na opinião de Miranda, comporta a apreciação de três categorias de escritores que incluem os portugueses que escreveram sobre a Índia e sua história no começo da empresa colonial; os portugueses que viveram na Índia e foram influenciados pela cultura desta; por fim, há uma última categoria que se refere à literatura goesa de expressão portuguesa. Sobre esta, Miranda explica que "por goesa ${ }^{7}$, queremos nos referir a pessoas etnicamente indianas de Goa que tiveram domínio perfeito da língua portuguesa e trataram de temas goeses ou, de qualquer modo, indianos" (MIRANDA, 2012, p. 18), portanto, a literatura goesa é entendida como uma categoria da mais ampla literatura indo-portuguesa e o seu estudo, nesse texto, limita-se às obras produzidas entre 1866 e 1963, um século de literatura.

Se bem que esta obra não pretenda ser uma história temática da literatura goesa, a intenção do autor é dissertar sobre os temas mais recorridos nesta literatura e analisá-los seguindo o método sócio-histórico, ou seja, tratando a matéria literária como documento social, para a reconstrução do contexto social e histórico goês daquela época. Embora Miranda se proponha estudar os textos como se fossem documentos sociais, a seleção que cumpre responde a um critério que é meramente estético (MIRANDA, 2012, p. 23), fundamentado não apenas nas próprias convinções, mas também no juízo dos seus predecessores Filinto Cristo Dias, Vimala Devi e Manuel de Seabra. Isto põe em discussão o propósito inicial de considerar essas obras pelo seu aspeto sociológico, por entrarem em jogo fatores, como a forma e o género, que se apartam dessa tipologia de estudo e dificultam o seu desenvolvimento linear. Na verdade, com exceção dos capítulos sobre a Índia-Mãe e a bailadeira do templo hindu que abordam um panorama de autores e obras maior, os

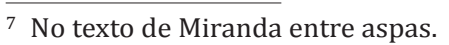

outros capítulos são uma análise dos quatro romances da literatura goesa publicados até o 1963, ou seja, os já citados Os Brâmanes, O Signo da ira, Jacob e Dulce e Bodki, cujos contextos históricos são aqui apenas esboçados.

Joana Passos, no seu Literatura Goesa em Português nos Séculos XIX e XX, define o método e enquadramento privilegiados por Miranda como “datados" (PASSOS, 2012, p. 19). De fato, apesar ter sido redigida em 1994 e publicada no 2012, é evidente que essa obra não é um trabalho atualizado, sobretudo se refletirmos à luz da mais recente abordagem pós-colonial dos estudos literários. Se bem que Miranda não avalie essa dimensão teórica, o que talvez represente a falta maior na sua obra é a carência de referências à Goa pós-independência e às transformações sociais e culturais aportadas por este acontecimento, considerando que O Signo da Ira de Orlando da Costa de 1961 é um romance explicitamente anticolonialista e Bodki de Agostinho Fernandes é publicado em 1963, dois anos depois da independência. Assim como falta uma certa fluidez na construção do percurso histórico, o que impede que haja uma conexão entre as diferentes temáticas tratadas e dificulta a compreensão desse fenómeno literário por parte do leitor desinformado.

Ao livro de Joana Passos deve ser reconhecido o mérito de ser o primeiro trabalho a dar um talhe crítico ao enfoque histórico. Com talhe crítico entendemos a argumentação teórica na qual a autora se baseia em definir o seu objeto de estudo, delimitar os períodos históricos a serem investigados e escolher as ferramentas para a análise da literatura em questão. $O$ fundamento teórico - defendido excelentemente pela pesquisadora - é extraído da recente tradição de estudos literários de molde pós-colonial que lhe permite destacar o caráter insurgente dessa literatura em relação ao regime colonial. Para discutir sobre este assunto, deveríamos nos remeter ao conceito de literatura goesa em português que Passos elabora e à sua diferenciação do 
conceito de literatura indo-portuguesa que a leva a contemplar a literatura de Goa apenas dos séculos XIX e XX.

Para Joana Passos por literatura goesa entende-se toda a literatura de caráter estético que foi produzida - e continua a ser - nas várias línguas que foram dominadas pelo povo goês, ou seja, concani, marathi, português e inglês. A literatura goesa de expressão portuguesa é apenas uma pequena parte dum mundo literário e é específica dos séculos XIX e XX, quando é possível detetar o começo de uma literatura que é híbrida - formada ao longo dos contactos entre a cultura do colonizador e a da população autóctone -, autónoma - que realiza uma função auto-representativa -, influenciada pelas manifestações literárias ocidentais, mas que leva em si um discurso de resistência ao poder colonial.

De forma oposta, a literatura indo-portuguesa distingue-se para adotar a Índia e Goa como "objetos de projetos e interesses que são exógenos às culturas locais" (PASSOS, 2012, p. 28), portanto, longe de ser o espelho de uma sociedade heterogénea em via de formação. Com isso, Passos refere-se à literatura dos séculos XVI, XVII e XVIII, composta basicamente por escritas de religiosos e navegantes quem Vimala Devi e Manuel de Seabra identificavam, na sua obra, como os precursores da literatura goesa. Sobre António Galvão e a escolha dos dois autores de defini-lo como o primeiro escritor da literatura goesa, Joana Passos escreve:

Como é que um autor que se refere a Portugal como "nossas partes" e publica em Lisboa é reclamado como parte integrante de uma literatura goesa por Devi e Seabra? Tal gesto faz sentido numa visão da literatura que depende do passaporte ou da natividade do autor, critério superficial por não ter necessária relação com a função, temática, ou estética de um texto. (PASSOS, 2012, 29)

Lembramos que Devi e Seabra distinguiam a literatura indo-portuguesa - datada na primeira metade do século VII - da literatura anterior, por ser a expressão da sociedade nascida da comunhão das culturas lusa e hindu; contrariamente, a literatura goesa inclui aqueles escritores que tiveram Goa como centro do próprio pensamento, mas que ficam alheios ao processo de formação cultural do seu povo. Passos subverte essa ideia, descrevendo a literatura indo-portuguesa como uma fase inicial da literatura goesa, relativa aos séculos XVI, XVII e XVIII, "segundo um critério que pode então ser de "representação e compreensão da Índia" em textos de língua portuguesa" (PASSOS, 2012, p. 29).

Outra problemática sublinhada por Passos tem a ver com o género literário a que pertencem os textos desses primeiros três séculos. Toda essa produção pode contar com relatos de viagens, relatórios administrativos e documentos de caráter religioso, os últimos redigidos com propósitos evangelizadores. $\mathrm{O}$ fato de serem produtos literários de caráter não ficcional e de se afastar duma função meramente estética, induz Joana Passos a não considerá-los como fundamentos de uma tradição literária goesa em português, sendo que no século XIX, quando irrompe "uma literatura laica e amena", esta procurará referências nos paradigmas estéticos dos cânones europeus (PASSOS, 2012, p. 30), contemporâneos aos seus expoentes e não nos seus predecessores goeses.

No que concerne a literatura religiosa, o questionamento desta é provocado pela sua natureza didascálica e pela sua funcionalidade ao desenvolvimento do projeto imperial, o que leva a autora do livro a deixá-la fora do seu trabalho, privilegiando a literatura laica dos séculos XIX e XX, julgada como iniciadora de uma cultura ativa e consciente em Goa, em oposição a essência repressiva e apagadora da literatura de cunho católico.

A novidade aportada por Literatura Goesa em Português nos Séculos XIX $e X X$ de Joana Passos é sem dúvida a assunção desta literatura em português como um microssistema literário no interno de um sistema plurilinguístico maior que é a literatura de Goa. No epílogo A Literatura Goesa no Presente, 
a autora aponta a possibilidade de construir novos estudos comparativos entre "as literaturas" de Goa e as outras literaturas indianas, promovendo a redação de resenhas críticas e traduções, assim como de trabalhos de compilação que ajudem a uniformizar essa literatura fragmentária. Com isso, dever-mos-ia fugir da ideia corrente de sistema literário, onde a língua é marca de identidade, para abordar uma nova conceção onde é a mesma literatura a ser a expressão da identidade goesa. Este discurso ganha força se pensarmos na literatura da diaspora goesa e na antologia compilada por Peter Nazareth Pivoting on the Point of the Return - Modern Goan Literature, publicada em 2010, que reúne romances, contos, poesias, ensaios políticos e de crítica literária, produzidos por autores goeses que escreveram a partir de Goa e por filhos da diáspora, entre os quais, muitos nem chegaram a pisar o solo goês em vida.

Peter Nazareth - goês nascido em Uganda e docente na University of Iowa, nos Estados Unidos - no prefácio admite as enormes dificuldades que comportou um trabalho tão ambicioso como o de juntar materiais espalhados pelo mundo inteiro. Dificuldades que se refletem na mesma tentativa de dar uma designação à literatura em objeto e estabelecer em que língua escreve o autor goês:

Many Goans, like West Indians, were living outside, yearning for home, refusing to be denationalized. I received writing by Goans about Goans, by Goans not about Goans, by non-Goans about Goans, by those who claimed one parent to be Goan, and by someone who had started an organization to trace ancestry through the mother. I discovered that Goans had written in at least thirteen languages, of wich the chief were English, Portuguese, Marathi and Konkani, the last of these, the mother tongue, being written in three different scripts. (NAZARETH, 2010, p. II)

A preocupação maior de Nazareth tem a ver com a literatura da diáspora, o que o leva a projetar uma secção do seu livro exclusivamente dedicada às escritas do exílio e do retorno - divida em the outside, the local e the return. Trata-se de uma literatura escrita predominantemente em inglês que ressalta a necessidade dos seus autores de restabelecer o contacto perdido com a terra natal, mas que ao mesmo tempo faz emergir toda a pluralidade das diferentes Goas dispersas no mundo, remetendo-nos ao seu hibridismo. Como problematizado no começo deste texto, talvez a diáspora seja um dos eventos que mais condicionou e dificultou o estudo das literaturas póscoloniais e no caso de Goa, este aspeto - tratado por Passos no seu livro também - é o que atualmente nos faz colocar a pergunta sobre a possível escrita de uma história única para a literatura goesa, apesar da sua natureza heterogénea e plurilinguística. Poderia isso, por acaso, contribuir à sua maior difusão, para que ela não permaneça ainda desconhecida? E quanto influiria, neste processo, a tradução da literatura escrita em português e concani para o inglês? Com certeza, não era isso o que tinham prognosticado Vimala Devi e Manuel de Seabra no epílogo da sua obra Perspectivas da Língua Portuguesa em Goa, onde apesar da tomada de consciência da eclipse do português em Goa e da crise da Imprensa em língua portuguesa depois da invasão de 1961, os dois autores ainda confiavam num futuro cor-de-rosa para a literatura indo-portuguesa, dado o fenómeno da auto-tradução que no pós-independência envolveu alguns escritores goeses como Laxmanrao Sardessai e R.V. Pandit. Assim como, uma das esperanças deles parecia ser alimentada pela presença de autores goeses em Portugal e no estrangeiro que continuavam a publicar livros em português sobre Goa (DEVI, SEABRA, 1971, p. 343-344), como o mesmo Orlando da Costa que é hoje considerado, para todos os efeitos, também um escritor da literatura portuguesa.

Talvez a solução de unificar todas as literaturas de Goa sob um único sistema literário possa simplificar o atingimento da sua historização, além de qualquer denominação conceitual, mas o risco que se correria seria deixar desapercebidas muitas peculiaridades caracterizantes as diferentes 
entidades literárias, relacionadas com os vários sistemas linguísticos que fizeram - no caso do português - e fazem parte da história plural de Goa.

\section{Referências}

ASHSCROFT, Bill; GRIFFITHS, Gareth; TIFFIN, Helen. The Empire Writes Back. Theory and Practice in Post-colonial Literatures. London, New York: Routledge, 1989.

DEVI, Vimala; SEABRA, Manuel. A Literatura Indo-Portuguesa. Lisboa: Juntas de Investigações do Ultramar, 1971.

DEVI, Vimala; SEABRA, Manuel. A Literatura Indo-Portuguesa. Antologia. Lisboa: Juntas de Investigações do Ultramar, 1971.

DIAS, Filinto Cristo. Esboço da História da Literatura Indo-portuguesa. Bastorá: Tipografia Rangel, 1963.

MIRANDA, Eufemiano de Jesus. Oriente e Ocidente na Literatura Goesa. Realidade, ficção, história e imaginação. Saligão: Goa 1556, 2012.

NAZARETH, Peter (Ed.). Pivoting on the Point of Return. Modern Goan Literature. Saligão: Goa 1556. Panjim: Broadway Book Centre, 2010.

PASSOS, Joana. Literatura Goesa em Português nos séculos XIX e XX: perspectivas póscoloniais e revisão crítica. Ribeirão: Humus, 2012.

Recebido em 19/04/2015.

Aceito em 11/08/20 